IMF STAFF DISCUSSION NOTE

\title{
Reforming Fiscal Governance in the European Union
}

Michal Andrle, John Bluedorn, Luc Eyraud, Tidiane Kinda, Petya Koeva Brooks, Gerd Schwartz, and Anke Weber 
IMF STAFF DISCUSSION NOTE

\section{Reforming Fiscal Governance in the European Union}

Michal Andrle, John Bluedorn, Luc Eyraud, Tidiane Kinda, Petya Koeva Brooks, Gerd Schwartz, and Anke Weber 


\section{INTERNATIONAL MONETARY FUND}

European Department in collaboration with the Fiscal Affairs and Research Departments

\section{Reforming Fiscal Governance in the European Union}

Prepared by Michal Andrle, John Bluedorn, Luc Eyraud, Tidiane Kinda, Petya Koeva-Brooks, Gerd Schwartz, and Anke Weber ${ }^{1}$

Authorized for distribution by Vitor Gaspar and Poul M. Thomsen

May 2015

DISCLAIMER: Staff Discussion Notes (SDNs) showcase policy-related analysis and research being developed by IMF staff members and are published to elicit comments and to encourage debate. The views expressed in Staff Discussion Notes are those of the author(s) and do not necessarily represent the views of the IMF, its Executive Board, or IMF management.

JEL Classification Numbers: $\quad$ E62, H60, H77

Keywords:

Fiscal Governance; Fiscal Policy; Fiscal Rules; European Economic

Authors' E-mail Addresses: and Monetary Union.

mandrle@imf.org; jbluedorn@imf.org; leyraud@imf.org; tkinda@imf.org; pkoeva@imf.org; gschwartz@imf.org; aweber@imf.org.

\footnotetext{
${ }^{1}$ The authors would like to thank for their comments Ali Abbas, Jochen Andritzky, Bergljot Barkbu, Craig Beaumont, Hugh Bredenkamp, Benedict Clements, Xavier Debrun, Vitor Gaspar, Amr Hosny, Ben Hunt, Daniel Leigh, Reza Moghadam, Dirk Muir, Christian Mumssen, Mahmood Pradhan, Murtaza Syed, Anna Ter-Martirosyan, and other IMF colleagues. We are also grateful to colleagues at the European Commission and the European Central Bank, and seminar participants at the April 2015 Banca d'Italia Public Finance Workshop in Perugia for their feedback.
} 


\section{CONTENTS}

EXECUTIVE SUMMARY

CONTEXT $\underline{5}$

THE SGP: PAST REFORMS AND CURRENT ISSUES $\mathbf{7}$

REFORM PROPOSALS $\underline{11}$

A. Simplifying the Framework __ 11

B. Consolidating the Preventive and Corrective Arms ___ 11

C. Shifting to a Single Fiscal Anchor with a Single Operational Rule __ 11

D. Improving Compliance __ 18

CONCLUSIONS

$\underline{20}$

BOX

1. Candidates for Operational Rules

$\underline{13}$

ANNEX

Simulations Design and Model Structure $\underline{21}$

REFERENCES $\underline{26}$

\section{FIGURES}

1. Average Public Debt Ratios of EU Members $\underline{6}$

2. Fiscal Consolidation and the Output Gap in the Euro Area__ $\underline{6}$

3. The EU Fiscal Framework__ $\underline{9}$

4. Noncompliance with European Fiscal Rules___ 10

5. Comparative Performance of Alternative Fiscal Rules__ $\underline{15}$

6. Measurement Errors and Public Debt with Real-Time Data __ 17

\section{TABLES}

1. Variability Around the Steady State ___ 15

A1. Fiscal Rule Parameterization__ $\underline{22}$

A2. GIMF Calibration Essentials___ 24

A3. Variance Around Steady-State, Detailed View___ $\underline{25}$ 


\section{EXECUTIVE SUMMARY}

The global financial crisis and its aftermath have tested the European Union's (EU) fiscal governance framework. The framework in place before the crisis had been useful to improve fiscal policymaking and coordination, but it ultimately did not prevent the buildup of fiscal imbalances. Public debt soared following the crisis in 2008 to an average of 95 percent in 2014-almost 30 percentage points above average precrisis levels. The experiences during the first decade of the European Economic and Monetary Union (EMU) and the euro area crisis led to major changes to the framework, including the 2005 reforms, the 2011 Six Pack, the 2012 Fiscal Compact, and the 2013 Two Pack. The successive reforms have helped to strengthen fiscal policy guidance, but they have also made the framework significantly more complex and difficult to operate, and concerns about compliance remain.

The purpose of this paper is to present options for simplifying the EU fiscal governance framework while enhancing its overall effectiveness. The current framework involves an intricate set of fiscal constraints. For example, both the preventive and corrective arms of the Stability and Growth Pact (SGP) constrain fiscal policies of EU member states through various targets, upper limits, and benchmarks. Fiscal policies are further constrained by the Fiscal Compact, which required countries to put in place national rules to ensure convergence toward medium-term objectives (MTOs). Overall, the framework has helped to strengthen policymaking and coordination, but compliance has remained weak, and the SGP's complexities have hampered effective monitoring and public communication.

The options presented in this paper would address these issues. In particular, they would:

- Simplify the overall fiscal governance framework design. An ambitious approach would involve merging the preventive and corrective arms of the SGP, and replacing it with a simple two-step procedure based on a common set of rules; this may potentially require substantial legal changes, including treaty changes. A less ambitious approach would seek to enhance the consistency between the two arms across different targets, upper limits, and benchmarks.

- Introduce a single fiscal anchor with a single operational rule. The paper argues for moving to a two-pillar approach with a single fiscal anchor (the public debt-to-GDP ratio) and a single operational target (an expenditure growth rule, possibly with an explicit, that is, formal and deterministic, debt-correction mechanism) linked to the anchor. This approach would help to safeguard fiscal sustainability and macroeconomic stability, while also facilitating monitoring and public communication.

- Further bolster enforcement. Several additional steps would improve implementation of the simpler fiscal framework and support compliance. These include: (1) greater automaticity in enforcement with a gradual step-up of monitoring and constraints; (2) a more credible set of sanctions that better reflect prevailing economic circumstances; and (3) a better coordination of fiscal policy monitoring between national fiscal councils and the Commission. 


\section{CONTEXT}

1. Fiscal governance framework: The centerpiece of the European Union (EU) fiscal governance framework is the 1997 Stability and Growth Pact (SGP). While it has evolved significantly over time, its origin dates back to the 1992 Maastricht Treaty and the inception of the European Economic and Monetary Union (EMU). The distinct structure of ongoing euro area integrationinvolving a common monetary policy and decentralized fiscal policies-called for mechanisms and rules to prevent national fiscal policies from imparting adverse spillovers to other countries and distorting the conduct of monetary policy (EC 2013). ${ }^{2}$

2. Framework under pressure: The global financial crisis has tested the EU fiscal governance framework and raised concerns about its effectiveness.

- Before the crisis, the existing fiscal governance provisions had not prevented the buildup of fiscal imbalances. For example, the public debt-to-GDP ratio increased steadily from an average level of below 60 percent of GDP in 1991 to more than 70 percent of GDP in the late 1990s, substantially above the level required by the 1992 Maastricht Treaty. Subsequently, a shallow reduction in the debt-to-GDP ratio during the 2000s reflected difficulties in building fiscal sufficient buffers in good times, as unsustainable domestic demand booms generated higher revenues that were mistakenly assumed to be permanent (Allard and others 2013). The buildup of imbalances also reflected the framework's inherent asymmetries, where ceilings are set on deficits in bad times without requiring surpluses in good times.

- When the crisis hit in 2008, EU member countries were ill-prepared. A severe economic downturn and large private-sector imbalances, which in part turned into public-sector liabilities, led to dramatic surges in debt ratios: public debt soared to an average of 95 percent in 2014almost 30 percentage points above average precrisis levels (Figure 1). This further strained fiscal rules, especially those that were set in nominal terms and did not foresee exceptional circumstances (IMF 2013). Failure to build sufficient buffers in good times led to the need to tighten fiscal policies in bad times (Figure 2).

\footnotetext{
${ }^{2}$ Throughout the note, we consider the terms targets, rules, constraints, ceilings, and upper limits as synonyms.
} 
Figure 1. Average Public Debt Ratios of EU Member Countries (percent of GDP)

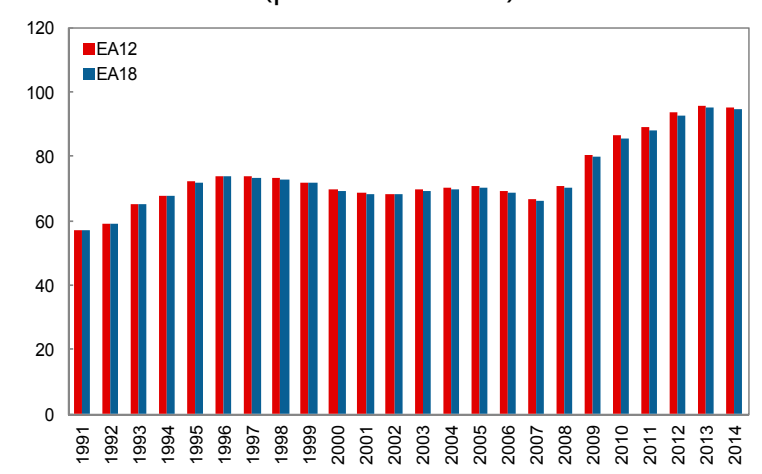

Source: European Commission Annual Macroeconomic (AMECO) database.
Figure 2. Fiscal Consolidation and the Output Gap in the Euro Area ${ }^{1 /}$

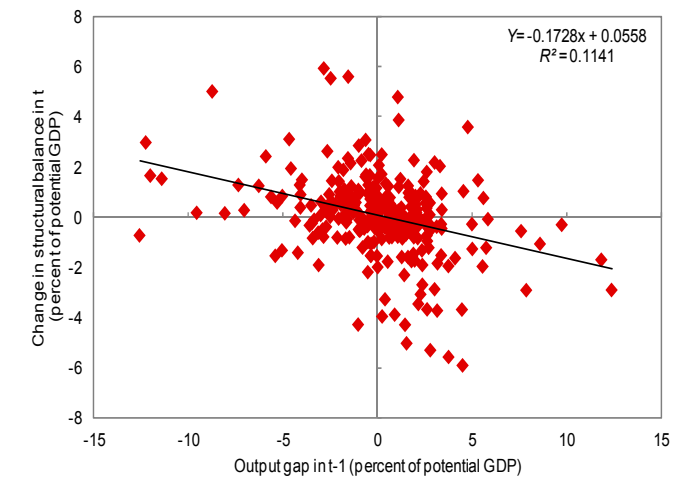

Source: AMECO database.

1/ Sample is the EA-18 from 1999-2013 (May 2014 database vintage) and 2014 (May 2015 database vintage).

3. Past reforms: The experience during the first decade of the EMU and the euro area crisis has led to important changes to the fiscal governance framework-including the 2005 reforms, the 2011 Six Pack, the 2012 Fiscal Compact, and the 2013 Two Pack. The successive revisions pursued several objectives, such as providing stronger economic underpinnings of the rules-based system; better aligning fiscal targets with the final debt objective; providing more flexibility while also strengthening enforcement mechanisms; and bringing more specificity to the definition of the rules. As such, these reforms have enhanced fiscal governance.

4. Views: While successive reforms have brought many positive elements to the framework and support the conduct of fiscal policy, they have also increased its complexity. The current fiscal governance system involves an intricate set of constraints, which complicates effective monitoring and public communication, and creates risks of inconsistency and overlap between the different parts of the system. Also, compliance remains weak. This reflects the complexity of the framework, which has resulted in both unintended violations and the exploitation of loopholes, and has gone hand-in-hand with weak enforcement. It would seem appropriate to discuss how the fiscal governance framework can be simplified and enforcement strengthened.

5. Scope: This paper presents options, which could be pursued over the medium term, to make the fiscal governance framework simpler, more transparent, and more robust. Section II discusses the characteristics and potential shortcomings in the EU's current framework. Section III examines reform options for simplification and stronger compliance. Section IV concludes the paper. The annex provides details on model simulations for different types of fiscal rules. The paper focuses on reform options that can be pursued over the medium term, and refrains from commenting on near-term issues, such as the flexibility in the existing fiscal framework or the appropriate aggregate fiscal stance in the euro area. 


\section{THE SGP: PAST REFORMS AND CURRENT ISSUES ${ }^{3}$}

6. Overarching objectives: The 1997 SGP provides a framework for governing national fiscal policies within the EU, aimed at safeguarding fiscal sustainability while also encouraging economic growth. ${ }^{4}$ The SGP contains a preventive and a corrective arm, where the former seeks to monitor and prescribe actions to avoid the buildup of fiscal imbalances, and the latter seeks to monitor and prescribe actions to redress excessive fiscal imbalances in EU member states.

7. Successive reforms: The current framework reflects successive layers of reform to the original 1997 framework, including the 2005 reforms, the 2011 Six Pack (five regulations and one directive), and the 2013 Two Pack (two regulations), as well as the Treaty on Stability, Coordination, and Governance of 2012 (TCSG, with the relevant articles referred to as the Fiscal Compact). ${ }^{5}$

- The 1997 SGP included three EU-wide rules: ceilings of 3 percent of GDP for the overall fiscal deficit and 60 percent of GDP for public debt (corrective arm), and a requirement for mediumterm budget positions to be "close to balance or in surplus" (preventive arm).

- The 2005 reform of the SGP aimed at enhancing the economic rationale underlying the rules and improving their flexibility by introducing country-specific medium-term objectives (MTOs) set in structural terms.

- The Six Pack reform in 2011 was designed to improve enforcement by adding an expenditure benchmark to the preventive arm and making the debt criterion in the corrective arm operational.

- The Fiscal Compact and Two Pack reforms of 2012 and 2013 reinforced monitoring and surveillance in the euro area and called for anchoring EU rules at the national level.

- In 2015, revised guidance on the implementation of the SGP increased its flexibility to encourage investment and structural reforms, and to account for the economic cycle.

8. Complex system: The current complexity of the framework (Figure 3) is rooted in this history of successive adjustments. Both the preventive and corrective arms of the SGP constrain fiscal policies of EU member states, including requiring them to converge towards the 60 percent of GDP debt target at a sufficient pace (the debt benchmark criterion); prohibiting them from breaching the 3 percent of GDP nominal deficit threshold; and mandating them to improve their structural balance-

\footnotetext{
${ }^{3}$ This paper draws extensively on the work done for the 2014 Euro Area Article IV Consultation; see Eyraud and Wu (2014, 2015).

${ }^{4}$ The SGP refers to the set of secondary legislation passed to establish a fiscal rule-based framework to monitor and coordinate national fiscal policies in the EU, and, in some circumstances, the euro area. The underlying legal basis for the SGP is in Articles 121 and 126 of the Treaty on the Functioning of the EU, one of the EU's founding treaties.

${ }^{5}$ The 2013 Two-Pack reforms apply only to euro area members.
} 
to-GDP ratio to a benchmark rate (see below) until they reach their country-specific MTOs, defined in structural terms. While increasing flexibility, the 2015 revised guidance on implementation of the SGP added another layer of complexity. The appropriate fiscal adjustment for member states in the preventive arm of the Pact will be defined using a matrix with five categories of economic conditions. ${ }^{6}$ Furthermore, government spending (net of new revenue measures) is constrained to grow in line with trend GDP (the expenditure benchmark). When countries are under the corrective arm (excessive deficit procedure or EDP), they are also subject to specific nominal and structural balance targets. Beyond these EU-wide constraints, the Fiscal Compact required signatories to put in place national rules, which may differ across countries, to ensure convergence toward their MTOs.

9. Related Risks: The elaborate set of fiscal constraints that make up the overall framework complicates effective monitoring, public communication, as well as national ownership and implementation. Implementation in particular is hampered by various overlaps, that may lead to inconsistencies or redundancies in the actions implied by the rules:

- First, the sheer number of rules poses an implementation burden on EU member states, hindering transparency. The EU imposes a larger set of constraints on member governments than most federations do; while the EU is not a federation, these are the closest comparators. For example, in a sample of 13 federations, Eyraud and Gomez (2014) find that the central government imposes, on average, two constraints on sub-central governments (states and substate entities), compared to five in the euro area. ${ }^{7}$

- Second, changes in underlying economic fundamentals have led to inconsistencies in the current configuration of numeric targets. For example, a 3 percent deficit target is consistent with a 60 percent debt level over the medium term only if nominal growth is slightly more than 5 percent. $^{8}$ However, potential growth has been revised down since the crisis, with mediumterm nominal growth now thought to be about 3 percent in many euro area economies. This implies a 100 percent of GDP debt level over the medium-term, resulting in an inconsistency between the existing debt and deficit targets; in other words, the action path implied by the deficit target diverges from that required by the debt target.

\footnotetext{
${ }^{6}$ As highlighted in EC communications, the five categories are (1) good times (output gap above 1.5\%); (2) normal times (output gap between $-1.5 \%$ and $+1.5 \%$ ); (3) bad times (output gap between $-3 \%$ and $-1.5 \%$ ); (4) very bad times (output gap between $-4 \%$ and $-3 \%$ ); and (5) exceptionally bad times (negative real growth or output gap below $-4 \%$ ). Member states are required to make a smaller fiscal effort during difficult economic conditions and a larger fiscal effort during better times.

${ }^{7}$ Given the complexity of the European framework, the numbering of rules is a matter of judgment. In our view, the framework has four main EU-wide rules-the 3 percent deficit rule, the 60 percent debt rule, an expenditure benchmark, and MTOs defined in structural terms. It also requires EU member countries to anchor a structural balance rule in national legislation.

${ }^{8}$ The nominal deficit-to-GDP associated with a stable debt-level (debt-stabilizing overall balance) is computed as $\left(\frac{D e f}{G D P}\right)^{*}=\left(\frac{D e b t}{G D P}\right)^{*}\left(\frac{g^{*}}{1+g^{*}}\right)$, in which the asterisk denotes steady-state values of the variables (Escolano 2010).
} 
Figure 3. The EU Fiscal Framework

Multiple Rules and Various Aggregates (as of mid-2014)

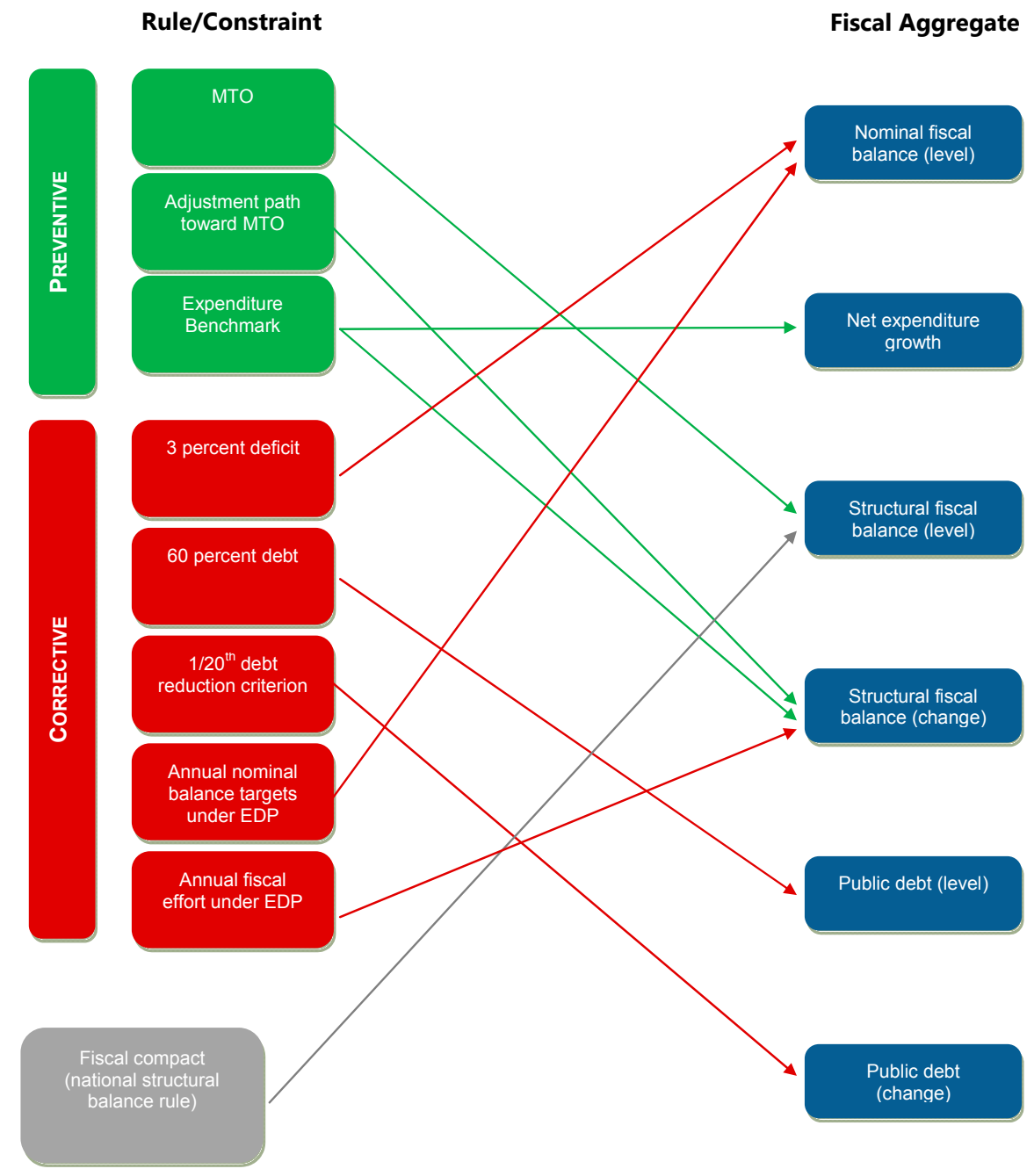

Note: $\mathrm{EDP}=$ excessive deficit procedure; $\mathrm{MTO}=$ medium-term objectives. The figure highlights key features; see EC 2013 for a fuller description.

Source: IMF staff.

- Third, the existing structural rules, like the MTOs, tend to be more binding in theory than the nominal targets, weakening the relevance of the latter (abstracting from measurement issues and the distinction between the corrective and preventive arms). For example, a back-of-theenvelope calculation indicates that the output gap would need to fall below -5 percent to make the nominal deficit target more relevant than the structural balance target for determining policy. ${ }^{9}$ Moreover, in general the structural balance rule (if followed) pushes the medium-term

\footnotetext{
${ }^{9}$ Assuming that a 1 percentage point drop in the output gap leads to a 0.5 percentage point deterioration of the nominal balance, a 3 percent of GDP nominal deficit appears with a structural deficit of 0.5 percent of potential GDP only if the output gap falls to -5 percent: $($ StructBal $)+\epsilon_{\text {NomBal,ouT }}($ OUTGAP $)=($ NomBal $) \rightarrow-0.5+0.5(-5)=-3$.
} 
debt level below 60 percent of GDP at a pace at least as fast as that required by the debtreduction criterion currently in place (see Eyraud and Wu 2015). ${ }^{10}$

- Fourth, the national rules required by the Fiscal Compact are not required to be identical to the EU-wide rules. For example, Germany has put in place national structural rules that are stricter than the EU-wide rules, with ceilings on the structural deficits set at 0.35 percent of GDP for the federal government from 2016 and at 0 percent (balance) for its constituent states from 2020 onward.

10. Weak compliance: The complex SGP framework has faced compliance issues, also reflecting weak pressures for enforcement (Figure 4).

- Since 1999, about half of the countries have missed the 60 percent target more than half of the time. Smaller countries have tended to be more compliant than larger countries. Moreover, the euro area as a whole has missed the target every year since 1999.

- $\quad$ Compliance has been better with the 3 percent nominal deficit ceiling. Most countries complied with it during the precrisis period (1999-2007), while both Greece and Portugal have failed to keep their deficit below 3 percent of GDP in most years since they joined the euro area.

Figure 4. Noncompliance with European Fiscal Rules
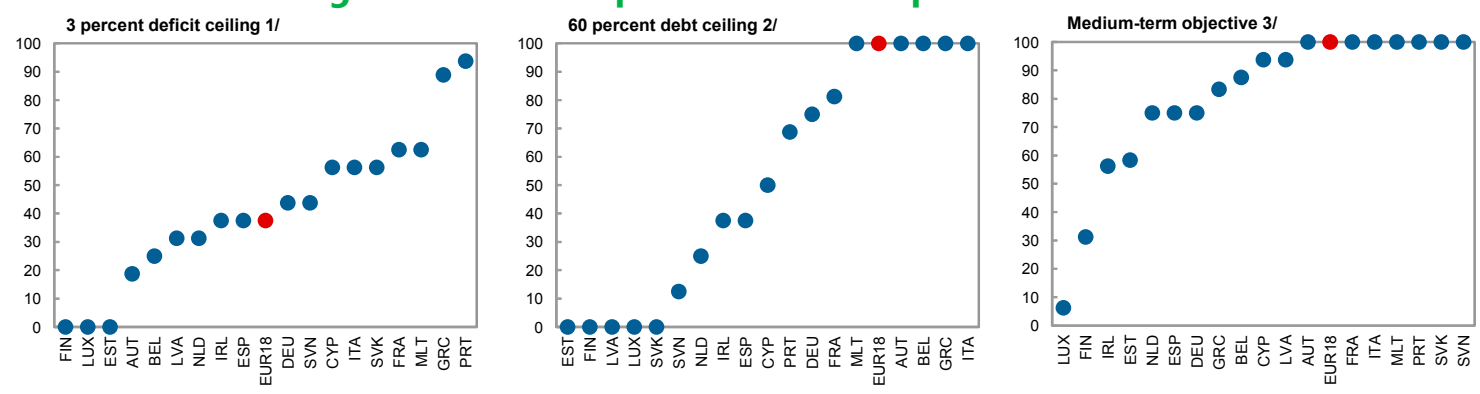

Source: AMECO database.

Note: The charts are not a formal evaluation of compliance because (1) they are based on ex post data; (2) targets are assumed to be similar across countries and time; and (3) they include all EA-18 countries, including those that joined EMU after 1999. Data labels in the figures use IOS country codes.

1 / Number of years with fiscal deficit above 3 percent divided by total number of years.

2/ Number of years with debt above 60 percent divided by total number of years.

3 / Number of years with structural deficit higher than 0.5 percent divided by total number of years.

\footnotetext{
${ }^{10}$ This result would not hold if the initial debt level is significantly above target.
} 


\section{REFORM PROPOSALS}

\section{A. Simplifying the Framework}

11. Premise: The underlying premise of this paper is that simplifying the current SGP framework and improving its enforcement mechanisms will help achieve a higher degree of fiscal and macroeconomic sustainability.

12. Legal obstacles: Implementing some of the proposals described next may require legal changes, going beyond changes in interpretations of existing laws. The issue of legal obstacles is raised briefly in the conclusion, but is not the focus of this paper.

\section{B. Consolidating the Preventive and Corrective Arms}

13. Rationale: To reduce complexities, the preventive and corrective arms of the SGP could be consolidated. Past revisions have already blurred the distinction between them. The preventive arm now includes many features of what would traditionally have been viewed as a corrective arm, including a structural balance target of no less than -0.5 percent (or -1 percent for countries below the 60 percent of GDP public debt ceiling), a convergence path toward the target if there is a deviation, escape clauses, and even sanctions. In addition, there is little economic rationale to putting a country into the tighter constraints of the corrective arm triggered by having breached the 3 percent nominal deficit limit, which only captures an annual flow.

14. Ambitious versus less ambitious: An ambitious approach, potentially requiring more substantial legal changes, would be to merge the two arms into a two-step procedure based on a common set of rules (Eyraud and Wu 2015). Minor slippages would trigger mild corrective actions, while cases of marked non-compliance could lead to enforcement of strong corrective actions and possibly sanctions. Along these lines, Debrun (2010) proposed to tie a country's exit from the corrective arm to meeting its MTO. A less ambitious reform would be to enhance consistency of the two arms across targets and benchmarks, similar to what was recently done to harmonize benchmarks for annual fiscal effort across the two arms.

\section{Shifting to a Single Fiscal Anchor with a Single Operational Rule}

15. Two-pillar approach: The dual objectives of safeguarding fiscal sustainability and maintaining simplicity suggest a two-pillar approach to the design of the fiscal framework, with $a$ single fiscal anchor and a single operational rule that acts as the lever that moves the anchor. A feedback mechanism between the anchor and the operational rule can either be formal (explicit), for example, in the form of an automatic debt correction mechanism, or less formal (implicit), for example, based on periodic ad hoc adjustments to correct deviations from the anchor. 
16. Fiscal anchor: The ultimate objective of the fiscal governance framework should be to ensure fiscal sustainability in the form of public debt sustainability. As a stock variable, the public debt-toGDP ratio is considered a natural anchor for capturing repeated (cumulative) fiscal slippages that flow variables, like the budget deficit, would not capture. Yet, public debt is affected by many factors, including public-sector financing operations that are unrelated to budget deficits (for example, fiscal contingent liabilities that are realized or valuation effects). Also, it has proven difficult to pinpoint a clear sustainability threshold beyond which fiscal sustainability can no longer be taken for granted (a discussion that is beyond the scope of this paper). However, as public debt sustainability is largely synonymous with fiscal sustainability, there is no good alternative to using the public debt-to-GDP ratio as the fiscal anchor.

17. Operational rule: The framework should also include an operational rule. A good operational rule should support countercyclical fiscal policy (economic stabilization) and provide a strong link to the fiscal anchor. Moreover, the rule should provide operational guidance (by being under the control of policymakers and having a direct link to discretionary measures) and be transparent (that is, easy to communicate to the public). ${ }^{11}$ There are three main types of operational rules: revenue rules; expenditure rules, and budget balance rules (expressed either in nominal or structural terms, where the latter can be defined in levels or first differences or a combination of them). See Box 1 and IMF (2009).

\footnotetext{
${ }^{11}$ The operational rule could be measured using either a "bottom-up" or "top-down" approach, or some average of the two. Bottom-up approaches assess the direct budgetary implications of discretionary policy measures, while topdown approaches take the headline overall balance and attempt to correct for the effects of the cycle, to recover the discretionary policy component of observed budgetary changes. The bottom-up approach is easier to communicate but harder to assess, while the top-down approach is easier to assess but harder to communicate. There are pros and cons to each method; we do not address the exact measurement choice in this note.
} 
Box 1. Candidates for Operational Rules

The main types of operational rules can be distinguished based on the type of budgetary aggregate that they seek to constrain; they have different advantages and disadvantages. The possible operational rules are the following:

Nominal budget balance rules. Budget balance rules constrain the variable that primarily influences the public debt ratio and can help ensure public debt sustainability. They are relatively easy to communicate to the public and largely under the control of policymakers. However, since they are specified in nominal terms, nominal budget balance rules do not have economic stabilization features and may lead to procyclical fiscal policies.

Structural balance rules. These are similar to nominal budget balance rules but explicitly take into account economic shocks and allow automatic stabilizers to operate. However, determining the required adjustment under a structural balance rule, typically also requires estimating an output gap, which makes it difficult to operate, communicate, and monitor the system. Structural balance rules can be supplemented with a debt correction mechanism ("debt brake") to correct for past deviations from the target, which adds further complexities.

Expenditure rules. Expenditure rules usually imply permanent limits on total, primary, or current spending in absolute terms, real growth rates (or real potential growth), or in percent of GDP. ${ }^{1}$ These rules are generally transparent (directly constraining the budget). They inherit many of the macroeconomic stabilization properties of a structural balance rule, by allowing for automatic stabilizers on the revenue side to operate fully. In addition, adequate specification of these rules (for instance, in real growth terms rather than in percent of GDP) tend to further support macroeconomic stabilization. While they are not linked directly to the debtsustainability objective (since they do not constrain the revenue side), they can trigger a required fiscal consolidation consistent with fiscal sustainability when they are accompanied by a debt brake. Yet the debt brake makes the system somewhat more complex to operate and more difficult to communicate to the public.

${ }^{1}$ For an in-depth discussion of design options for expenditure targets, see Ljungman (2008).

18. Evaluating operational rules: We assess the ability of three operational rules-the overall (nominal) balance, the structural balance, and real expenditure growth-to deliver macroeconomic stabilization in the form of debt sustainability. This is done on the basis of stochastic simulations that are applied to a stylized model of a euro area economy, and allow us to evaluate how different operational rules perform over the course of the business cycle. ${ }^{12}$ The simulations are based on the historical distribution of demand shocks over the past three decades, and show the counterfactual historical performance of these rules in terms of achieving debt sustainability for the stylized euro area economy. ${ }^{13}$ In some cases, a debt correction mechanism is included to link the rule to the

\footnotetext{
12 There are some differences between the expenditure benchmark in the SGP and the expenditure growth rule used in the simulations. While the simulations use a simple expenditure growth rule based on total expenditure, the SGP expenditure benchmark makes a number of adjustments to total expenditure. The expenditure benchmark in the SGP is based on real expenditures net of interest payments, cyclical unemployment benefits, and discretionary revenue measures. Those adjustments allow for a greater degree of counter-cyclicality to the associated target than what we consider in the simulations. Moreover, to allow for countercyclical changes in public investment, the SGP expenditure benchmark uses smoothed capital expenditures instead of actual or expected capital expenditures.

${ }^{13}$ It is a global, three-region, general-equilibrium model (a variant of the IMF's Global Integrated Monetary and Fiscal (GIMF) model), with a euro area country (calibrated to Italy), an "other euro area country" aggregate, and the Rest of the World. The stochastic simulations are carried out around the steady-state, implying lower debt levels than those
}

(continued) 
anchor explicitly and avoid permanent deviations from the anchor. A debt correction mechanism maps the current deviation of the debt from its target level to the policy action prescribed by a rule; for example, having debt above its target may imply an additional tightening over and above what the simplest rule might prescribe (see the annex for further details). In all cases, government spending is assumed to be the fiscal instrument that is adjusted to meet the rule (again, see the annex for some discussion regarding the results for fiscal adjustment via alternative fiscal instruments).

19. Model simulation results: Two main robust findings emerge from the simulations (Figure 5 and Table 1):

- Economic stabilization: The lowest variability of output is achieved by the expenditure growth rule, which ties down real expenditure growth to the economy's potential or trend growth rate, combined with a debt correction mechanism (to ensure convergence toward the fiscal anchor). Structural balance rules combined with a debt correction mechanism are a very close second (nearly identical). Nominal balance rules, which do not allow for a buildup of debt and deficits during the cycle, perform worst in terms of output variability.

- Debt stabilization: The lower volatility of output under the expenditure growth and structural balance rules comes at the cost of a more volatile debt-to-GDP ratio. This reflects the fact that both rules allow for the operation of automatic stabilizers (partially in the case of expenditure growth and fully in the case of the structural balance). By contrast, the nominal budget balance rule does well in terms of the volatility of the public debt-ratio. The debt correction mechanism is an important component for most fiscal governance frameworks, since it does not increase volatility of output by much and may significantly reduce the volatility of the debt ratio in the long-term. While our simulated debt correction mechanism is endogenous to the fiscal rule and automatically corrects deviations from the debt objective ("debt brake"), other debt correction mechanisms can also be considered. For instance, the expenditure rule could set spending growth below potential output growth (by a fixed margin) over a pre-defined period. This would also ensure convergence of debt toward a lower debt objective. An exogenous, pre-defined path of debt adjustment might however fail to be stabilizing if the economy is subject to larger than expected shocks.

currently observed in many euro area economies. As the model does not feature strong nonlinearities, the results and ordering of various rules would not materially differ if carried out around the consolidation path, where the representative euro area economy would be converging from a higher debt level to its desired, steady-state debt level. The aggregate demand shocks are drawn from their estimated, historical distribution and used to build a history, which is then combined with the particular rules that are being simulated. The outturns from this exercise are then collected, and, building over multiple histories of shocks, provide a picture of the average behavior of economic variables of interest (like GDP growth and inflation) under each fiscal-rule option. Following general consensus (see, for example, Christiano, Motto, and Rostagno 2014), demand shocks are considered the primary drivers of business cycles. See the annex for further details. 
Figure 5. Comparative Performance of Alternative Fiscal Rules (variability around the steady-state; standard deviations)

Figure 5. Comparative Performance of Alternative Fiscal Rules
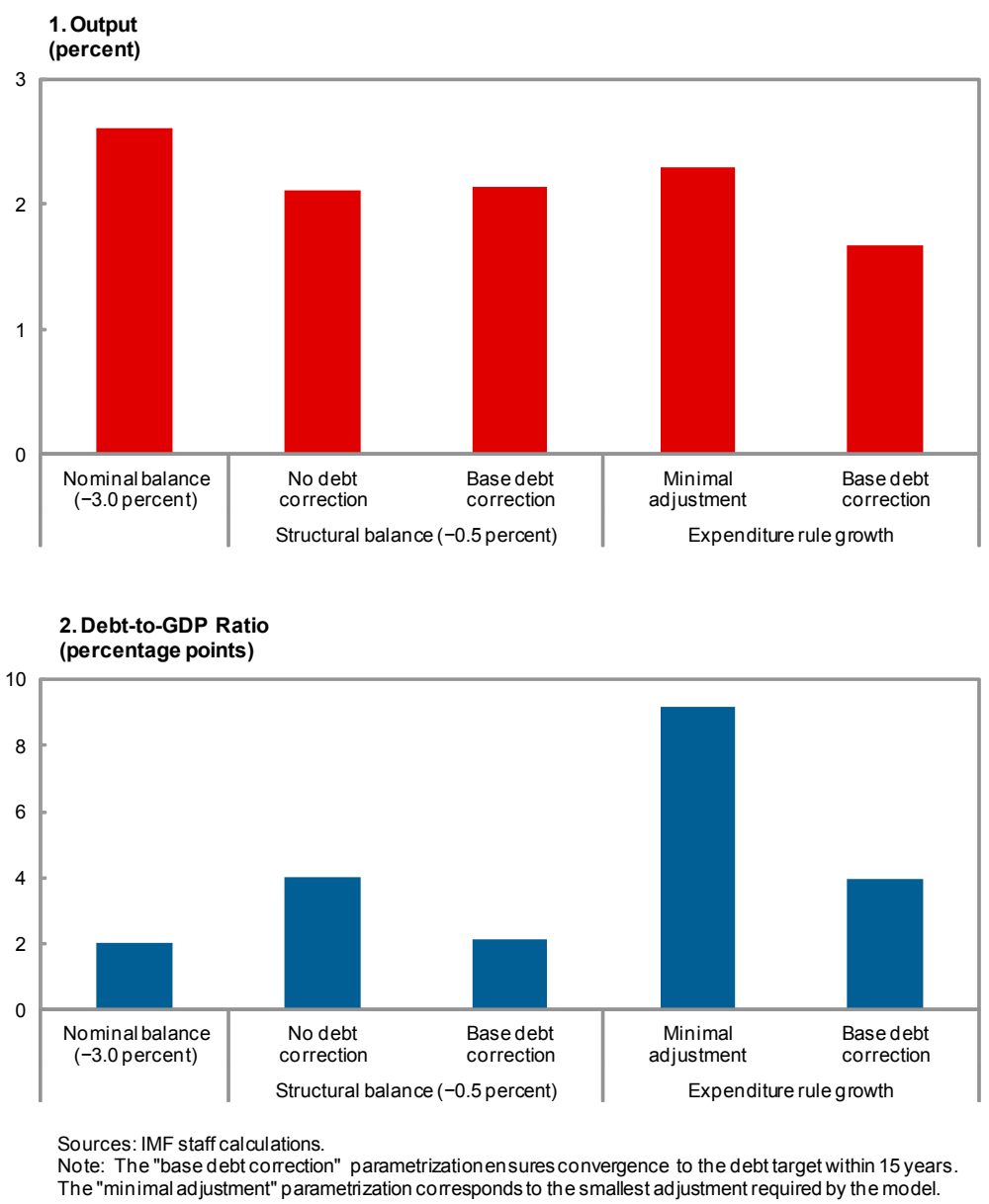

Table 1. Variability around the Steady-State (Standard Deviations)

\begin{tabular}{lccc}
\hline Type of fiscal rule & $\begin{array}{c}\text { Output } \\
\text { (percent) }\end{array}$ & $\begin{array}{c}\text { Output Growth } \\
\text { (pp) }\end{array}$ & $\begin{array}{c}\text { Debt-to-GDP } \\
\text { (pp) }\end{array}$ \\
\hline Nominal balance (-3 percent) & 2.6 & 1.8 & 2.0 \\
Nominal balance (0 percent) & 2.4 & 1.6 & 0.0 \\
Structural balance (-0.5 percent) & 2.1 & 1.1 & 4.0 \\
Structural balance (-3 percent) & 2.3 & 1.2 & 5.6 \\
Structural balance (-0.5 percent) w/ debt correction (base) & 2.1 & 1.2 & 2.1 \\
Structural balance (-0.5 percent) w/ debt correction (weak) & 2.1 & 1.1 & 2.8 \\
& & & \\
Expenditure growth rule w/ minimal adjustment & 2.3 & 0.8 \\
Expenditure growth rule w/ debt correction (base) & 1.7 & 0.6 & 9.2 \\
\hline Source: IMF staff calculations. & & & 4.0 \\
\hline
\end{tabular}

Note: Simulations with three-region IMF GIMF model for aggregate demand shocks. See the main text and annex for additional details. pp= percentage points. 
20. Additional considerations: The simulations suggest that expenditure rules and structural balance rules perform similarly well and clearly outperform nominal budget balance rules in stabilizing the economy. To decide between the two leading contenders, other considerations have to be taken into account.

21. Operational guidance and transparency: Different considerations suggest that expenditure rules would better meet the dual objectives of providing operational guidance and achieving transparency than structural balance rules. First, expenditure rules are more directly related to the formulation of the annual budget, which sets legally binding spending appropriations, thereby providing clear operational guidance to policymakers. Second, expenditure rules are less complex and therefore easier to communicate and monitor.

22. Recent literature: The recent literature also gives strong support to using expenditure rules. For example, using a different simulation model and a simpler expenditure rule, Debrun, Epstein, and Symansky (2008) and Kinda (2015) show that an expenditure growth rule with a feedback mechanism from debt ensures a convergence toward the debt objective, while allowing greater flexibility in response to shocks. Petrova (2012) also demonstrates that an expenditure growth ceiling performs well against several criteria (stabilization, transparency, and fiscal discipline), when it is supplemented with a debt correction mechanism. More recently, Carnot (2014) shows that a rule targeting primary expenditure growth (adjusted for discretionary revenue measures) relative to trend output growth can strike a good balance between the objectives of long-term sustainability and short-term macroeconomic stabilization, while being tractable. Cordes and others (2015) also provide an indepth discussion of expenditure rules and illustrate that compliance with them is generally better than with other fiscal rules because they are transparent and generally easy to monitor.

23. Measurement uncertainty: While our findings are in line with recent literature, a key shortcoming of the above model-based stochastic simulations is that they assume perfect measurement of the output gap. In practice, the levels of potential GDP and the output gap are difficult to measure, particularly in real-time, leading to large ex-post adjustments. This is true for both structural balance rules that rely on output gap measurements, as well as expenditure rules that are linked to potential growth. However, the use of potential growth-rather than the level of potential GDP or the output gap-makes expenditure rules more robust, as revisions to potential growth tend to be smaller (see below). To illustrate this, we use simple deterministic simulations and compare the performances of the expenditure and structural balance rules if they had been applied for Italy and France. In contrast to the model simulations above, these deterministic simulations are backward looking and do not incorporate stochastic shocks.

24. Assumptions: To do so, real-time data are constructed such that the one-year ahead forecast of the October World Economic Outlook in year $t-1$ constitutes the information set available to policymakers when setting up budget plans for year $t$. The simulations assume that between 2001 and 2014 countries had followed either an expenditure or structural balance rule. The expenditure 
rule limits expenditure growth to a 10-year moving average of real GDP growth. ${ }^{14}$ The structural fiscal balance (SFB) rule requires countries to be at their MTO (set at -1 and -0.5 percent for France and Italy, respectively). We use a fiscal multiplier of 0.5 before 2008 and 0.75 after 2008 (both declining to zero in five years) to estimate the output effect of the implicit fiscal shock corresponding to the difference between spending in the baseline and in the fiscal rule scenarios. ${ }^{15}$

Figure 6. Measurement Errors and Public Debt Evolution with Real-Time Data
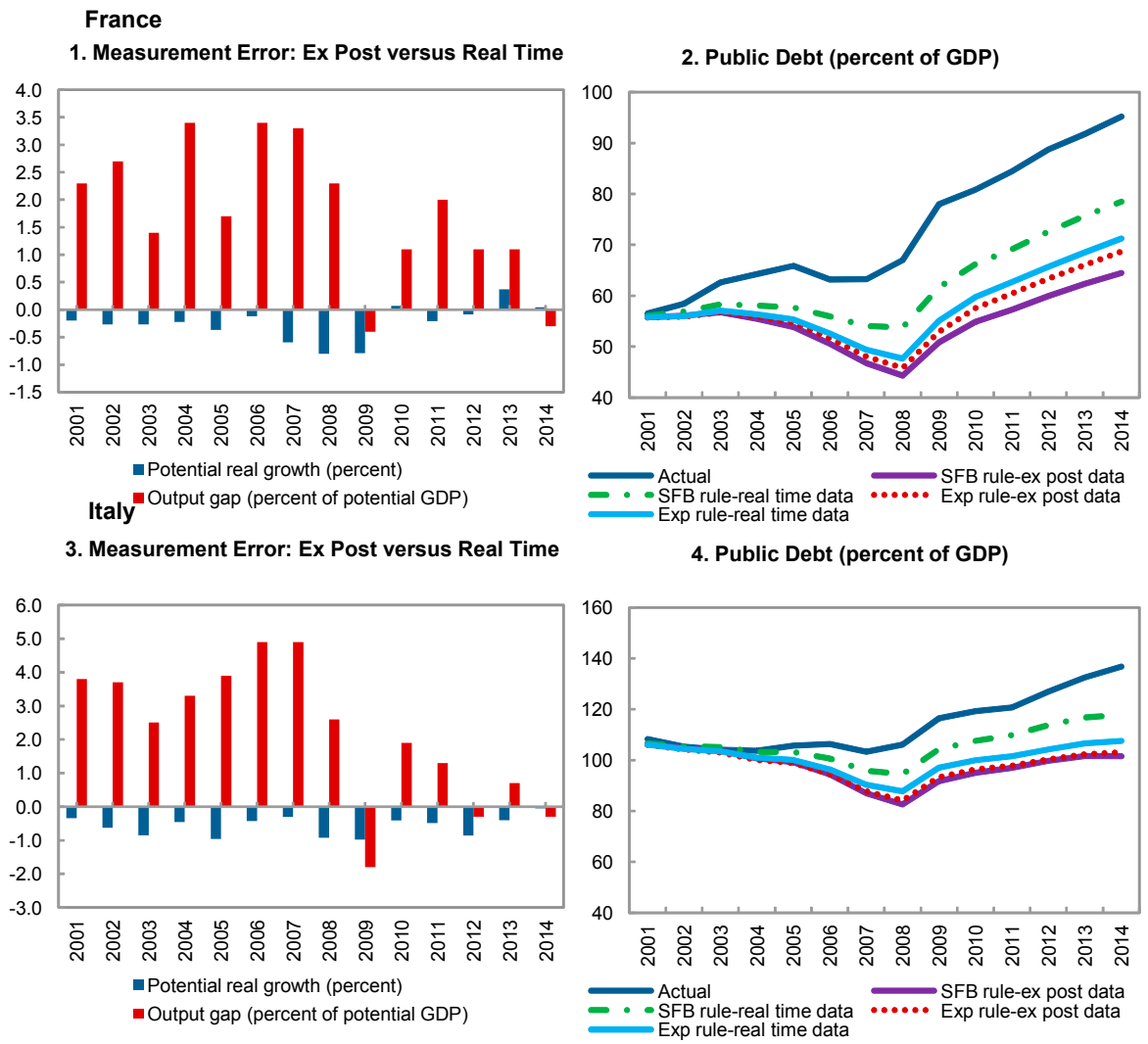

Source: WEO and IMF staff calculations.

Note: Ex post data are from the October 2014 WEO, while the real-time data for year $t$ are the projected values given in the year $t-1$ October WEO. Measurement errors are taken to be the difference between the two.

\footnotetext{
${ }^{14}$ The 10-year moving average in period $t$ is constructed as the average of real GDP growth between $t-5$ and $t+4$ as a proxy for potential growth. The construction is analogous to that used in the EU expenditure benchmark. We do not exclude any items from expenditure.

${ }^{15}$ Empirical evidence shows that multipliers were higher during the crisis than in normal times (for a literature summary, see Batini, Eyraud, and Weber [2014]). The simulations assume that under both the structural balance and expenditure rules, the adjustment to meet the target is made through spending. We compute the difference between historical expenditure (the baseline) and what spending would have been under the rules (both in real time and ex post). This measure of discretionary fiscal policy, together with the fiscal multiplier, is then used to adjust the baseline (historical) output level.
} 
25. Illustration: The results show that the difference between real time and ex-post outcomes under the expenditure rule would have been significantly smaller than for the structural balance rule (Figure 6). For the expenditure rule, the difference in public debt between real-time and ex-post data in 2014 is about 3 percent for France and 4 percent for Italy. For the structural balance rule, it is 14 percent for France and 16 percent for Italy. This is because measurement errors are much smaller for potential GDP growth (the expenditure rule) than for the output gap (the structural balance rule).

26. Specific parameters: The discussion here abstracts from the important issue of the exact parameterization of the rules, which can be calibrated to be more or less strict. There is a trade-off between the strictness of the rules and the need for discretionary flexibility through well-defined escape clauses. When the rules are very strict and hard to abide by when economic circumstances deteriorate, it may be helpful to have some flexibility in the framework. This will enable a better response to shocks and avoid pressures to abandon (or modify) the rules in an ad hoc manner.

27. Escape clauses: The current SGP already contains an area-wide escape clause for "exceptional circumstances," such as natural disasters, periods of severe economic downturns, or large accumulated losses in output relative to potential. To further strengthen the flexibility of the proposed fiscal framework against stagnation risks, conditions to activate the symmetric escape clause could include a large accumulated loss of nominal output that may arise with a prolonged period of low inflation or deflation in the euro area (symmetric refers to the clause being equally applicable across all euro area economies when activated). ${ }^{16}$

28. Bottom line: We conclude that there is a good case for using public debt-to-GDP as the single fiscal anchor and an expenditure growth rule (possibly including an explicit debt correction mechanism) as the single operational target. Other indicators (such as the structural balance and its change) could provide supplementary evidence on the appropriateness of fiscal actions, while keeping the expenditure growth rule as the sole binding rule. That said, there are several assumptions and judgments used in the evaluation here that argue for approaching the conclusions with some degree of caution. For instance, different weights on the relative importance of the fiscal objectives may lead to a different selection.

\section{Improving Compliance}

29. Beyond design problems: The reforms discussed above will address some of the shortcomings of the current framework by reducing its complexity and addressing underlying design and measurement issues. In particular, the reforms will reduce the number of numerical rules, address the problem of weak incentives to build sufficient buffers in good times, and do away with

\footnotetext{
${ }^{16}$ IMF staff estimates suggest that the impact on public finances of low inflation can be quite pronounced. Simulations for five euro area economies (France, Ireland, Italy, Portugal, and Spain) suggest that a 1 percent downward surprise in inflation would raise the public debt-to-GDP ratio by 1.4-1.7 percent in the first year and 2.93.8 percent in the second year (Tapsoba and Weber 2014).
} 
the need to estimate the level of potential output. However, simplification by itself will not resolve problems of weak compliance: even a simple framework can be circumvented. The unique surveillance and coordination procedures within the EMU pose challenges to enforcement mechanisms, which are not as strong as in federations. Although the relative "weakness" of the supranational level in the EU would call for stronger enforcement tools, sanctions and corrective actions are relatively mild in Europe (Eyraud and Gomez 2014). Beyond the technical dimensions, effective enforcement importantly requires a clear buy-in to the mechanisms by participating member states.

30. Reform options: To enhance enforcement and further improve compliance, a number of options could be considered:

- Greater automaticity in enforcement: More automaticity could be introduced in the gradual step-up of monitoring and constraints after a country is found to be in breach of the rules. However, the imposition of sanctions should remain a discretionary decision based on a sound economic judgment of their appropriateness, guided by the Commission. ${ }^{17}$

- More credible sanctions: The set of sanctions considered may also need to reflect economic circumstances; financial sanctions lack credibility in bad times, as they exacerbate the troubles of already distressed governments. Such sanctions might be more effective in good times, while non-pecuniary sanctions could be used in bad times. For example, administrative sanctions (such as constraints on new hiring by governments) might be considered.

- Better coordination of fiscal policy monitoring: Formal cooperation between national fiscal councils and the Commission could reduce the risk of conflicting assessments. Such cooperation can take place through regular meetings between fiscal councils and the EC in a multilateral setting-for instance in the context of the EU Network of Independent Fiscal Institutions (EUNIFI).

31. Market discipline: Complementary to formal enforcement mechanisms, market discipline could also improve compliance. However, market discipline was relatively ineffective before the crisis, reflecting the lack of credibility of the "no-bailout" provisions of the Treaties for a set of highly integrated economies in the face of a systemic crisis (Allard and others 2013). While important in bolstering fiscal moderation, enhancing market discipline is a long-term endeavor.

32. A "center-based" approach: In the absence of effective market discipline, better guidance to national fiscal decisions could take various forms. These include legal challenges at the national level, leverage to sanction with a larger central budget, and a veto power from the center. Many of

\footnotetext{
${ }^{17}$ Although explicit sanctions are allowed in cases of non-compliance, they have not yet been used. The latest reforms, in particular the introduction of reverse qualified majority voting at the Council to overturn a decision by the Commission to impose sanctions, should help make enforcement more automatic and less subject to political interference by increasing the hurdle for objection.
} 
these options would entail a permanent loss of fiscal sovereignty for euro area members (for instance, if a veto power of the center on national budgets was introduced). Of course, a larger role for the center raises difficult questions about political and democratic accountability for European and euro area decision bodies. See Allard and others (2013) for a fuller discussion and analysis of options for greater fiscal integration in the euro area.

\section{CONCLUSIONS}

33. Lessons: The global financial crisis and its aftermath have pointed to the need for strengthening the design and enforcement of the EU fiscal governance framework. Notwithstanding recent revisions, the EU fiscal governance framework remains complex, and compliance and enforcement fairly weak. With public debt at record highs, it would seem desirable to redesign the fiscal governance framework to prevent a further buildup of fiscal imbalances and better support fiscal and macroeconomic sustainability.

34. Main Proposals: A simplified fiscal framework centering on two main pillars: a single fiscal anchor (public debt-to-GDP) and a single operational rule (an expenditure growth rule, possibly with an explicit debt correction mechanism) linked to the anchor. Greater automaticity in enforcement, a more credible set of sanctions, and better coordination of fiscal policy monitoring could further support the implementation of the simplified framework.

35. Reform hurdles: The transition toward a new steady-state fiscal framework will take time. Some reforms may face legal obstacles, and wholesale treaty changes may be needed. However, working for a simpler and more robust fiscal framework may be the best response to recent skepticism about the European project. 


\section{Annex. Simulations Design and Model Structure}

1. The model used for the stochastic simulations is a three-region version of the IMF's Global Integrated Monetary and Fiscal (GIMF) model; see Kumhof and others (2010) and Anderson and others (2013) for in-depth descriptions. It features a representative euro area country (in this case Italy), an aggregate of the rest of the euro area, and an aggregate of the rest of the world. There are two types of consuming households in the model: (1) Blanchard-Yaari type overlapping generations, intertemporally optimizing households, and (2) liquidity constrained, hand-to-mouth households. Both types of households supply their labor to firms in traded and non-traded goods sectors. Final and intermediate goods are produced using labor and capital goods, with varying capacity utilizations. The capital investment decision of firms is subject to financial frictions with an external financing premium that increases with the leverage of entrepreneurs (like the Bernanke-GertlerGilchrist vein of financial accelerator mechanisms).

2. Countries internationally trade both final and intermediate goods, as well in international euro-denominated nominal bonds. Monetary policy authorities in the euro area as a whole and in the aggregate of the rest of the world operate under inflation targeting regimes following a Taylor rule for nominal policy rate. The exchange rate between the euro area and rest of the world freely floats.

3. Household and firms pay labor and corporate taxes, and consumption is subject to valueadded tax. Governments use their revenues to finance transfers to households, public consumption, and productive government investment, which has positive productivity spillovers to private producers. The government in the representative euro area country follows an explicitly specified fiscal rule that ensures the long-term sustainability of public debt. In each and every period the rule must assure that households and firms believe the government is intertemporally solvent.

4. The nominal and structural balance fiscal rules considered are nested in the following specification:

$$
\text { Def }_{t}=\text { Def }^{*}-\alpha\left(\text { OutputGap }_{t}\right)-\beta\left(\text { Debt }_{t-1}-\text { Debt }^{*}\right),
$$

in which the deficits and debt are relative to GDP, in percent, and the output gap is relative to the level of potential output, in percent as well. In the case of the structural balance rule $\alpha=0.45$, while it is zero for the nominal balance rule. Further, $\beta$ is the coefficient on the debt correction mechanism. The expenditure growth rule takes the form:

$$
100 * \log \left(E X P_{t}\right)=100 * \log \left(\alpha Y_{t}^{*}\right)-\delta\left(D e b t_{t-1}-D e b t^{*}\right),
$$

in which $\delta$ drives the strength of a debt-brake. Expenditures growth follows the potential output growth, adjusted for debt stabilization. 
5. The debt correction coefficient, $\beta$ and $\delta$ are calibrated for each rule to achieve a debt-to-GDP ratio convergence within a specified number of years, with a given half-life. Structural balance rule with no debt correction implies debt convergence in more than 40 years after the initial shock, with a half-life of 15 years. In the case of weak debt correction, it takes up to 40 years for debt to reach its target after the shock, with the half-life of 13 years. With stronger debt correction it takes up to 15 years to converge, with the half-life of 7 years. In the case of the expenditure rule the "base" debt correction is parameterized to converge within 15 years, with the half-life of 6 years. The calibration of all fiscal rules is detailed in Table A1. The expenditure rule with "minimal" debt adjustment is a rule with the smallest value of the debt correction term that is feasible within the model.

\section{Table A1. Fiscal Rule Parameterization}

\begin{tabular}{lllr} 
Fiscal Rule & \multicolumn{3}{l}{ Parameterization } \\
\hline Nominal balance rule & $\alpha 0.00$ & $\beta$ & 0.00 \\
Structural balance rule & $\alpha 0.45$ & $\beta$ & 0.00 \\
Structural balance rule + debt corr. (base) & $\alpha 0.45$ & $\beta$ & 0.125 \\
Structural balance rule + debt corr. (weak) & $\alpha 0.45$ & $\beta$ & 0.05 \\
Expenditure rule: (minimal) & $\gamma 0.00$ & $\delta$ & 0.50 \\
Expenditure rule: w/ debt corr. & $\gamma 0.00$ & $\delta$ & 0.95 \\
\hline
\end{tabular}

Source: IMF staff calculations.

6. The rest of the model is calibrated for the three regions so that the steady-state matches their average stylized facts (such as the shares of consumption and investment in GDP), while the model's dynamic properties reflect those observed in the data (drawing upon the IMF's experience with this and other macro models) over the course of the business cycle. The representative euro area country amounts to about 16 percent of the euro area. The euro area represents roughly 20 percent of the world model economy. The calibration of the representative country broadly follows calibration of Italy, with the exception of the steady-state level of debt and deficit ratio to GDP. Further, it is assumed that there exists a debt-elastic sovereign premium in the euro area, which adds about 7 basis points for each increase of debt-to-GDP by 100 basis points. ${ }^{1}$ See Table A2 for some essential calibration ratios and parameters and Anderson and others (2013) for more on GIMF model properties. Note that government transfers include, for example, pensions and social welfare payments, while government consumption includes, for example, the government wage bill.

7. As mentioned in the main text, the stochastic simulations focus on aggregate demand shocks drawn from their historical, estimated distribution, based on the variability of the annual output gaps in the last couple of decades. ${ }^{2}$ To obtain those we have used an estimated output gap for Italy and

\footnotetext{
${ }^{1}$ The calibration of the debt-elastic sovereign premium is within the range of estimates seen in the literature and used by the OECD (for example, Haugh, Ollivaud, and Turner 2009).

${ }^{2}$ Other shocks such as supply shocks, financial shocks, and monetary policy shocks can also be simulated. The analysis focuses on demand shocks as they dominate business cycle fluctuations and are fairly simple to simulate.
} 
rest of the euro zone and backed out the distribution of the shock needed to match the output gap dynamics. The shock distribution is then used to generate the stochastic simulations. An identical path of simulated shocks is used to evaluate all fiscal rules, hence there is no randomness involved in the comparison.

8. Table A3 then shows the long-run variability, unconditional, around the steady-state of each variable for the representative country, conditional on histories of aggregate demand shocks drawn from the estimated distribution. We believe this statistics captures well the idea that the goal is to evaluate the feasibility of fiscal rules over the course of multiple business cycles. As in the case of every model simulation exercise, it is rather a stylized one. It offers, however, a stock-flow consistent general-equilibrium environment to test various forms of fiscal rules, as compared to the often used partial equilibrium framework.

9. Some elementary robustness analysis was carried out. The main body of the text presents the fiscal rules that share a common instrument-government spending (consumption and investment). Other instruments were simulated, namely lump-sum transfers and labor and consumption tax rates. A robust finding is that all rules perform best when non-distortionary lump-sum transfers are used as an instrument, as one would expect based on economic theory. Also, no combinations of fiscal instruments for a given rule were presented in the main text. But one of the best-performing rules is when government spending responds to the output gap in a countercyclical way, while lump-sum transfers are the balancing instrument for long-term debt sustainability. The implied variance of all rules also changes in relation to the steady-state deficit-to-GDP ratio, be it 0 percent, 0.5 percent, or 3 percent, respectively. When increasing the steady-state deficit the variance of the economy rises as more adjustment of fiscal instruments is needed to stabilize public finances. ${ }^{3}$ The relative ordering, however, does not change. Table A3 illustrates a version of nominal and structural balance rules with lump-sum transfers as instruments and with differences in the steady-state deficit-to-GDP ratio.

10. The simulation focuses on a representative euro area country and the rest of the euro area. The calibration of the representative euro area country already implies a rather limited effect of the country on the area-wide inflation and interest rate. Larger countries would, however, affect the euro area total in a more substantive way. Relative variances do vary with the relative size of the country but the robust findings about the importance of the debt correction and instrument preference (transfers versus spending) are left unchanged. For idiosyncratic shocks the smaller is the country, the more important is the effect of the debt-elastic risk premium as it further diminishes the effects of area-wide monetary policy.

\footnotetext{
${ }^{3}$ Note that even with a 3 percent deficit-to-GDP ratio the primary balance must be in surplus in the steady state, since the economy is efficient (real rates are higher than real growth).
} 
Table A2. GIMF Calibration Essentials

\begin{tabular}{|c|c|c|c|c|}
\hline Steady-State Shares & Units & EA Country & Rest of EA & RoW \\
\hline GDP & $\%$ world GDP & 3.2 & 16.6 & 80.2 \\
\hline Labor share & $\%$ GDP & 60.0 & 60.0 & 60.0 \\
\hline Consumption & $\% \mathrm{GDP}$ & 60.3 & 59.3 & 60.0 \\
\hline Private investment & $\% \mathrm{GDP}$ & 17.4 & 16.6 & 20.0 \\
\hline Government spending & $\% \mathrm{GDP}$ & 22.3 & 24.1 & 20.0 \\
\hline Consumption & $\%$ GDP & 20.4 & 21.7 & 17.0 \\
\hline Investment & $\% \mathrm{GDP}$ & 1.9 & 2.4 & 3.0 \\
\hline Exports & $\%$ GDP & 22.8 & 26.2 & 5.6 \\
\hline Imports & $\% G D P$ & 29.6 & 26.2 & 5.6 \\
\hline NFA/GDP & $\%$ GDP & 0.0 & 0.0 & 0.0 \\
\hline \multicolumn{5}{|l|}{ Government Finances } \\
\hline Government Deficit/GDP & $\%$ GDP & 3.0 & 3.0 & 2.2 \\
\hline \multicolumn{5}{|l|}{ Government Spending } \\
\hline Consumption & $\%$ GDP & 20.4 & 21.7 & 17.0 \\
\hline Investment & $\%$ GDP & 1.9 & 2.4 & 3.0 \\
\hline Transfers & $\%$ GDP & 20.0 & 15.8 & 8.3 \\
\hline \multicolumn{5}{|l|}{ Government Revenue } \\
\hline Labor tax & $\%$ GDP & 24.9 & 23.0 & 22.5 \\
\hline Corporate & $\%$ GDP & 2.2 & 2.4 & 16.0 \\
\hline Consumption & $\%$ GDP & 12.3 & 10.1 & 15.0 \\
\hline \multicolumn{5}{|l|}{ Key Parameters } \\
\hline Intertemporal EoS(1) & & 0.5 & 0.5 & 0.5 \\
\hline Habit persistence & & 0.4 & 0.4 & 0.4 \\
\hline EoS Home/Foreign goods & & 1.5 & 1.5 & 1.5 \\
\hline Home bias in consumption & & 0.8 & 0.8 & 0.8 \\
\hline \multicolumn{5}{|l|}{ Monetary policy rule } \\
\hline Interest rate smoothing & & & 0.3 & 0.3 \\
\hline Inflation gap & & & 1.5 & 1.5 \\
\hline Output gap & & & 0 & 0 \\
\hline Govt' debt-elastic premium & bp per100bp & 7 & 7 & 7 \\
\hline
\end{tabular}

Source: IMF staff calculations.

Note: $E A=$ euro area; $b p=$ basis point; $E O S=$ elasticity of substitution;

NFA = net foreign assets; RoW = rest of the world. 
Table A3. Variance Around Steady-State, Detailed View

\begin{tabular}{|c|c|c|c|c|c|c|c|}
\hline Type of fiscal rule & Instrument & $\begin{array}{c}\text { Output } \\
\text { (percent) }\end{array}$ & $\begin{array}{c}\text { Output Growth } \\
\text { (pp) }\end{array}$ & $\begin{array}{c}\text { Debt-to-GDP } \\
\text { (pp) }\end{array}$ & $\begin{array}{c}\text { Surplus-to-GDP } \\
\text { (pp) } \\
\end{array}$ & $\begin{array}{l}\text { Premium } \\
\text { (pp) }\end{array}$ & $\begin{array}{c}\text { Real Rate } \\
\text { (pp) }\end{array}$ \\
\hline Structural balance (- 0.5 percent) & transfers & 1.4 & 0.8 & 2.7 & 0.4 & 0.2 & 0.3 \\
\hline Structural balance (-3 percent) & transfers & 1.5 & 0.8 & 3.8 & 0.5 & 0.2 & 0.3 \\
\hline Nominal balance (-3 percent) & transfers & 1.3 & 0.8 & 1.2 & 0.0 & 0.1 & 0.3 \\
\hline Nominal balance (-3 percent) & spending & 2.6 & 1.8 & 2.0 & 0.0 & 0.1 & 0.3 \\
\hline Nominal balance (0 percent) & spending & 2.4 & 1.6 & 0.0 & 0.0 & 0.0 & 0.4 \\
\hline Structural balance (- 0.5 percent) & spending & 2.1 & 1.1 & 4.0 & 0.7 & 0.3 & 0.3 \\
\hline Structural balance (-3 percent) & spending & 2.3 & 1.2 & 5.6 & 0.7 & 0.4 & 0.3 \\
\hline Structural balance (- 0.5 percent) $w /$ debt corr. (base) & spending & 2.1 & 1.2 & 2.1 & 0.6 & 0.1 & 0.3 \\
\hline Structural balance (- 0.5 percent) w/ debt corr. (weak) & spending & 2.1 & 1.1 & 2.8 & 0.6 & 0.2 & 0.3 \\
\hline Expenditure growth rule $\mathrm{w} /$ minimal adjustment & spending & 2.3 & 0.8 & 9.2 & 0.8 & 0.6 & 0.5 \\
\hline Expenditure growth rule w/ debt corr. (base) & spending & 1.7 & 0.6 & 4.0 & 0.8 & 0.3 & 0.2 \\
\hline
\end{tabular}

Source: IMF staff calculations. 


\section{References}

Allard, C., P. Koeva Brooks, J. Bluedorn, F. Bornhorst, K. Christopherson, F. Ohnsorge, T. Poghosyan, and an IMF staff team. 2013. "Towards a Fiscal Union for the Euro Area." IMF Staff Discussion Note 13/09, International Monetary Fund, Washington. https://www.imf.org/external/pubs/ft/sdn/2013/sdn1309.pdf.

Anderson, D., B. Hunt, M. Kortelainen, M. Kumhof, D. Laxton, D. Muir, S. Mursula, and S. Snudden. 2013. "Getting to Know GIMF: The Simulation Properties of the Global Integrated Monetary and Fiscal Model." IMF Working Paper 13/55, International Monetary Fund, Washington. https://www.imf.org/external/pubs/ft/wp/2013/wp1355.pdf.

Batini, N., L. Eyraud, and A. Weber. 2014. "A Simple Method to Compute Fiscal Multipliers." IMF Working Paper 14/93, International Monetary Fund, Washington. http://www.imf.org/external/pubs/ft/wp/2014/wp1493.pdf.

Carnot, N. 2014. "Evaluating Fiscal Policy: A Rule of Thumb." European Economy Economic Papers 526, European Commission, Brussels. http://ec.europa.eu/economy finance/publications/economic paper/2014/pdf/ecp526 e n.pdf.

Christiano, L., R. Motto, and M. Rostagno. 2014. "Risk Shocks." American Economic Review, 104(1): 27-65.

Cordes, T., T. Kinda, P. Muthoora, and A. Weber. 2015. "Expenditure Rules: Effective Tools for Sound Fiscal Policy." IMF Working Paper 15/29, International Monetary Fund, Washington. www.imf.org/external/pubs/ft/wp/2015/wp1529.pdf.

Debrun, X. 2010. "Gaps in the Euro Area Fiscal Framework: Options for a New Fiscal Contract." Euro Area Policies: Selected Issues, IMF Country Report 10/222, International Monetary Fund, Washington. https://www.imf.org/external/pubs/ft/scr/2010/cr10222.pdf.

Debrun, X., N. Epstein, and S. Symansky. 2008. "A New Fiscal Rules: Should Israel Go Swiss?" IMF Working Paper 08/87, International Monetary Fund, Washington. https://www.imf.org/external/pubs/ft/wp/2008/wp0887.pdf.

Escolano, J. 2010. "A Practical Guide to Public Debt Dynamics, Fiscal Sustainability, and Cyclical Adjustment of Budgetary Aggregates." IMF Technical Notes and Manuals 2010/2, International Monetary Fund, Washington. https://www.imf.org/external/pubs/ft/tnm/2010/tnm1002.pdf. 
European Commission (EC). 2013. "Building a Strengthened Fiscal Framework in the European Union: A Guide to the Stability and Growth Pact." Occasional Papers 150, Brussels. http://ec.europa.eu/economy finance/publications/occasional paper/2013/pdf/ocp150 e n.pdf.

Eyraud, L., and R. Gomez. 2014. "Constraints on Subnational Fiscal Policy." In Designing a European Fiscal Union: Lessons from the Experience of Fiscal Federations, edited by C. Cottarelli and M. Guerguil, Routledge. London: Routledge.

Eyraud, L., and T. Wu. 2014. "Fiscal Governance in the Euro Area: Progress and Challenges." Euro Area: Selected Issues Paper, IMF Country Report 14/199 International Monetary Fund, Washington. http://www.imf.org/external/pubs/ft/scr/2014/cr14199.pdf.

_ 2015. "Playing by the Rules: Reforming Fiscal Governance in Europe." IMF Working Paper 15/67, International Monetary Fund, Washington. http://www.imf.org/external/pubs/ft/wp/2015/wp1567.pdf.

Haugh, D., P. Ollivaud, and D. Turner. 2009. "What Drives Sovereign Risk Premiums?: An Analysis of Recent Evidence from the Euro Area." OECD Economics Department Working Paper No. 718, OECD Publishing, Paris. http://dx.doi.org/10.1787/222675756166

International Monetary Fund (IMF). 2009. "Fiscal Rules-Anchoring Expectations for Sustainable Public Finances." IMF Policy Paper, Washington. http://www.imf.org/external/np/pp/eng/2009/121609.pdf.

_ 2013. "Reassessing the Scope and Modalities of Fiscal Policy in Advanced Economies." IMF Policy Paper, Washington. http://www.imf.org/external/np/pp/eng/2013/072113.pdf.

Kinda, T. 2015. "Anchoring Sustainable Fiscal Policy: A New Fiscal Rule in Canada." Selected Issues Paper, IMF Country Report 15/23, International Monetary Fund, Washington. http://www.imf.org/external/pubs/ft/scr/2015/cr1523.pdf.

Kumhof, M., D. Laxton, D. Muir, and S. Mursula. 2010. "The Global Integrated Monetary and Fiscal Model (GIMF) - Theoretical Structure." IMF Working Paper 10/34, International Monetary Fund, Washington. http://www.imf.org/external/pubs/ft/wp/2010/wp1034.pdf.

Ljungman, G. 2008. "Expenditure Ceilings: A Survey." IMF Working Paper 08/282, International Monetary Fund, Washington. https://www.imf.org/external/pubs/ft/wp/2008/wp08282.pdf. 
Petrova, I. 2012. "Iceland's Policy Objectives Under a New Fiscal Rule." Selected Issues Paper, IMF Country Report 12/90, International Monetary Fund, Washington. https://www.imf.org/external/pubs/ft/scr/2012/cr1290.pdf.

Tapsoba, J., and A. Weber. 2014. "'Lowflation' and Its Potential Impact on Public Finances." IMF Fiscal Affairs Department Internal Note, International Monetary Fund, Washington. 